\title{
A STUDY OF CORROSIVE INJURY OF UPPER GASTROINTESTINAL TRACT- STUDY OF SURGICAL ASPECTS OF ACUTE STAGE AND ITS SEQUELAE
}

\author{
Abhineet Kumar Jain ${ }^{1}$, Dinesh Chaudhari², Geetesh Ratre ${ }^{3}$ \\ ${ }_{1}^{1}$ Senior Resident, Department of General Surgery, NSCB Medical College, Jabalpur, Madhya Pradesh, India. \\ ${ }^{2}$ Senior Resident, Department of General Surgery, SMBT Medical College, Nashik, Maharashtra, India. \\ ${ }^{3}$ Resident, Department of General Surgery, NSCB Medical College, Jabalpur, Madhya Pradesh, India.
}

\begin{abstract}
BACKGROUND
Corrosive injury to upper gastrointestinal tract is an agonizing experience for both patient and treating physician. Though formulations of household cleansing agents have become safer in recent times, corrosive injury still remains common clinical problem in many countries particularly India. Lye is most commonly ingested caustic in west. Acid ingestion is a commoner cause of upper gastrointestinal tract injury in our country. Childhood injuries are usually accidental while suicide is frequent motive in young adults.
\end{abstract}

ABSTRACT

\section{METHODS}

This is a prospective observational study. All the patients who presented to the Emergency Department or OPD in M.Y. hospital with history of Corrosive Agent Ingestion from Year March 2016 to July 2017 were included in the study.

\section{RESULTS}

In our study, the most common symptom is dysphagia which was present in 95\% (59/62), chest pain 65\% (40/62), vomiting 47\% (29/62), abdominal pain 15\% (9/62), drooling of secretions $60 \%(37 / 62)$, Hematemesis $10 \%(6 / 62)$. The site of lesion is predominantly oesophagus with $23 \%$ mid oesophagus (14/62), $19 \%$ distal oesophagus (11/62), $23 \%$ involving both mid and distal oesophagus (14/62), stomach 16\% (10/62) and single case involving duodenum. Seven out of 62 patients presented to us with signs of acute abdomen with X-ray abdomen revealing gas under diaphragm. Three patients after adequate resuscitation were taken for exploratory laparotomy. Remaining four patients succumbed to resuscitation. $27 \%(16 / 62)$ had severe oesophageal injury. In our study, oesophageal stricture was present in $75 \%$ cases (46/62), gastric outlet obstruction in $16 \%$ cases (10/62), epigastric pain due to GERD in $20 \%$ cases $(12 / 62)$.

\section{CONCLUSIONS}

Corrosive injury of the upper gastrointestinal tract is a common problem with variable clinical presentations. Acid injury is more common in developing countries like India. The depth of injury is the most important determinant of the outcome. Early endoscopy is helpful in assessing the extent of injury to plan future management of the patient. Nutritional support is given by total parenteral nutrition and feeding jejunostomy. Nasogastric tube and antibiotics have no role in preventing stricture. Endoscopic dilatation is the treatment of choice for oesophageal stricture. Surgery remains the last option for endoscopic failure and for patients who develop complications on endoscopic dilatation.

HOW TO CITE THIS ARTICLE: Jain AK, Chaudhari D, Ratre G.A study of corrosive injury of upper gastrointestinal tract- study of surgical aspects of acute stage and its sequelae. J. Evolution Med. Dent. Sci. 2019;8(19):1582-1587, DOI: 10.14260/jemds/2019/350

\section{BACKGROUND}

Corrosive injury to upper gastrointestinal tract is an agonizing experience for both patient and treating physician. Though formulations of household cleansing agents have become safer in recent times, corrosive injury still remains common clinical problem in many countries particularly INDIA. Lye is most common ingested caustic in west, Acid ingestion is a commoner cause of UGI tract injury in our country. Childhood injuries are usually accidental while suicide is frequent motive in young adults.

'Financial or Other Competing Interest': None.

Submission 19-03-2019, Peer Review 24-04-2019,

Acceptance 30-04-2019, Published 13-05-2019.

Corresponding Author:

Dr. Dinesh Chaudhari,

Flat No. 2, A/16,

Gopika Apartment,

Kasturba Society, Vishrantwadi,

Pune-411015,

Maharashtra, India.

E-mail:choudhari.dj@gmail.com

DOI: $10.14260 /$ jemds $/ 2019 / 350$
The scenario of corrosive injury has changed over last 30 years. Before 1967, most cases reported were due to ingestion of solid lye in form of particles, flakes, granules. Ingestion of solid lye usually produces damage to lips, oral cavity and larynx. Oesophageal injury and strictures were less common because of intense burning of lips or buccal mucosa limited the quantity of acid ingested. Introduction of liquid lye as a drain cleanser led to an increase in incidence of oesophageal and gastric burns. Since 1970, many such products for household use have been reformulated or withdrawn from market in countries like USA.

However, these agents especially acids, are easily available in the Indian market. Corrosive agents commonly ingested include strong acids like sulphuric acid and hydrochloric acid and strong alkalis like sodium hydroxide and Potassium Hydroxide. Ammonia and Sodium hypochlorite are examples of weak acid and alkali respectively. Acid injuries seem to be more common in India because acids being cheaper than alkalis. Corrosive substances are easily accessible to common people including children. These substances are used commonly in the form of toilet cleaning agents, soaps, bleaches, disc batteries, etc. Corrosive injuries are unique to 
third world countries as corrosive poisons are commonly available and are used as mode of suicide

The ingestion of corrosive substances has devastating effects on the upper gastrointestinal tract and present major problems in their management. These injuries occur as accidental/ suicidal or homicidal intentions and under the influence of alcohol or drugs in case of adults.

\begin{tabular}{|c|c|}
\hline Injury & Findings \\
\hline Grade 0 & Normal mucosa \\
\hline Grade 1(Superficial) & Superficial hyperaemia and oedema \\
\hline $\begin{array}{c}\text { Grade 2a } \\
\text { (Transmucosal) }\end{array}$ & $\begin{array}{c}\text { Haemorrhage, exudates, } \\
\text { linear erosions, blisters, shallow } \\
\text { ulcers involving the mucosa and } \\
\text { submucosa }\end{array}$ \\
\hline Grade 2b & Circumferential burn present \\
\hline Grade 3 & $\begin{array}{c}\text { Deep ulceration, eschar formation } \\
\text { with necrosis, full thickness injury } \\
\text { with and without perforation }\end{array}$ \\
\hline $\begin{array}{c}\text { Grading of the Oesophageal Burns which were Caused by } \\
\text { Caustic Injury }\end{array}$ \\
\hline $\begin{array}{c}\text { The Grade 1 and 2 injuries were managed conservatively and } \\
\text { the patients were advised follow up. The grade 3 and 4 } \\
\text { injuries required surgery and follow up. }\end{array}$ \\
\hline
\end{tabular}

Acids and alkalis in various forms cause different patterns of injuries. The management of such injuries is multidisciplinary, which involves reducing the morbidity and mortality by accurate early diagnosis, aggressive treatment of the life threatening complications and an attentive, long term follow up. Caustic ingestion can cause severe injury to the oesophagus and the stomach.

The severity and the extent of the oesophageal and the gastric damage which results from a caustic ingestion depends upon the following factors.

(1) Corrosive properties of the ingested substance Amount, (2) concentration, (3) physical form (solid or liquid) of the agent (4) Duration of contact with the mucosa.

These ingestions are the leading cause of oesophageal strictures.

In long term management of patients with acute caustic intoxications, some difficulties related to late complications exist. They happen quite often and are usually very extensive. Advanced diagnostics and modern approaches have reduced the percentage of post corrosive late complications of upper gastro intestinal tract. Nevertheless, they still present a major medical and social issue, both by their clinical presentation and therapeutic protocols. Also, post corrosive late complications restrict patients everyday life.

The most common late complications are oesophageal strictures and stenosis, gastric stenosis of antrum and pylorus and oesophagus and stomach cancer. Predictions in acute caustic poisonings are very alterable and they depend on the degree of oesophageal and gastric lesions as well as the general health condition of the patient. The highest mortality rate has been recorded as a result of perforation and mediastinitis.

Both observational and aggressive surgical strategies have been advocated for the treatment of corrosive injuries of the upper gastrointestinal tract (UGT) but the optimal management is still a dilemma. The aim of this study was to report our experience with caustic UGT injuries in adult patients treated with a surgically aggressive, endoscopy-based therapeutic protocol over a 1-year period.

\section{Objectives of The Study}

1. To determine the aetiopathological pattern of chemical injuries of the upper gastrointestinal tract.

2. To evaluate the incidence, mode of injury, socio economic status, educational background, initial phase management and the surgical aspects of treatment acute stage corrosive injuries of upper gastrointestinal tract and its sequelae.

\section{METHODS}

\section{Study Design}

A combined retrospective, prospective study. An observational study.

The study was conducted after taking proper consent of the patient. All the patients who presented to the Emergency Department or the Out Patient Department in M.Y. hospital with history of Corrosive Agent Ingestion from year March 2016 to July 2017.

Data collected include patient's age, sex, corrosive agents, mode of injury, clinical features, complications improvement in comorbid conditions.

Follow up was done after surgery and improvement in associated comorbidities. Total number of cases was 62 .

\section{Inclusion Criteria}

All patients with history of corrosive substance ingestion in age group 15-80 years.

Psychiatric patients that limit the patients' ability to understand the procedure will be included in the study and consent will be taken from their LAR.

\section{Exclusion Criteria}

1. The patients who had consumed other substance were excluded from study.

2. All the patients with inadequate follow up.

3. Previously diagnosed anomaly of gastrointestinal tract.

\section{Statistical Methods}

The Statistical Package for Social Science \{SPSS Version 20 will be used for Data Analysis

- Mean, median, and SD are used to describe quantitative data.

- Qualitative data are summarized using frequency and percentage

\section{RESULTS}

\begin{tabular}{|c|c|}
\hline Age & No. of Patients \\
\hline $15-25$ & 27 \\
\hline $26-35$ & 30 \\
\hline $36-45$ & 1 \\
\hline $46-55$ & 3 \\
\hline $56-65$ & 0 \\
\hline $65-75$ & 1 \\
\hline$>75$ & 0 \\
\hline Table 1. Age Wise Distribution of Patients \\
\hline
\end{tabular}

\begin{tabular}{|c|c|c|}
\hline Sex & No. of Patients & Percentage \\
\hline Females & 23 & 38 \\
\hline Males & 39 & 62 \\
\hline \multicolumn{3}{|c|}{ Table 2. Sex Distribution } \\
\hline
\end{tabular}




\begin{tabular}{|c|c|c|}
\hline Type of Corrosive & No. of Patients & Percentage \\
\hline Acid & 57 & 92 \\
\hline Alkali & 5 & 8 \\
\hline \multicolumn{2}{|c|}{ Table 3. Types of Corrosives } \\
\hline
\end{tabular}

\begin{tabular}{|c|c|c|}
\hline Mode of Injury & No. of Patients & Percentage \\
\hline Suicidal & 46 & 74 \\
\hline Accidental & 15 & 24 \\
\hline Homicidal & 1 & 2 \\
\hline \multicolumn{3}{|c|}{ Table 4. Mode of Injury } \\
\hline
\end{tabular}

\begin{tabular}{|c|c|c|}
\hline Clinical Feature & No. of Patients & Percentage \\
\hline Chest pain & 40 & 65 \\
\hline Hematemesis & 6 & 10 \\
\hline Vomiting & 29 & 47 \\
\hline Dysphagia & 59 & 95 \\
\hline $\begin{array}{c}\text { Drooling of } \\
\text { secretions }\end{array}$ & 37 & 60 \\
\hline Abdominal pain & 9 & 15 \\
\hline \multicolumn{2}{|c|}{ Table 5. Clinical Feature } \\
\hline
\end{tabular}

\begin{tabular}{|c|c|c|}
\hline Site of Lesion & No. of Patients & Percentage \\
\hline Mid Oesophagus & 23 & 37 \\
\hline Distal Oesophagus & 13 & 20 \\
\hline Mid \& Distal Oesophagus & 9 & 14 \\
\hline Proximal Oesophagus & 1 & 1 \\
\hline Stomach & 15 & 24 \\
\hline Duodenum & 1 & 1 \\
\hline \multicolumn{2}{|c|}{ Table 6. Site of Lesion } \\
\hline
\end{tabular}

\begin{tabular}{|c|c|c|}
\hline Management & No. of Patients & Percentage \\
\hline Conservative & 1 & 1 \\
\hline Oesophagectomy & 13 & 20 \\
\hline Gastric Pull Up & 10 & 16 \\
\hline Colonic Pull Up & 3 & 4 \\
\hline GJ & 14 & 21 \\
\hline FJ & 58 & 93 \\
\hline Oesophageal Dilatation & 29 & 49 \\
\hline
\end{tabular}

Table 7. Management

\begin{tabular}{|c|c|c|}
\hline Complication & No. of Patients & Percentage \\
\hline Stricture & 46 & 74 \\
\hline Gastric Outlet Obstruction & 10 & 16 \\
\hline Tracheooesophageal Fistula & 0 & 0 \\
\hline Hiatus Hernia, GERD & 12 & 19 \\
\hline Carcinoma & 1 & 1 \\
\hline Chest Complication & 3 & 4.6 \\
\hline \multicolumn{3}{|c|}{ Table 8. Sequelae of Corrosive Ingestion } \\
\hline
\end{tabular}

\begin{tabular}{|c|c|c|}
\hline Socio Economic & No. Patients & Percentage \\
\hline Low & 47 & 77 \\
\hline Middle & 15 & 23 \\
\hline High & 0 & 0 \\
\hline \multicolumn{2}{|c|}{ Table 9. Socio-Economic Status } \\
\hline
\end{tabular}

\begin{tabular}{|c|c|c|}
\hline Psychiatric Illness & No. of Patients & Percentage \\
\hline Alcohol & 27 & 43 \\
\hline Tobacco & 6 & 10 \\
\hline Both & 3 & 5 \\
\hline Depression & 40 & 64 \\
\hline \multicolumn{2}{|c|}{ Table 10. Associated Comorbidity or Addictions } \\
\hline
\end{tabular}

\begin{tabular}{|c|c|c|}
\hline Stay in Days & No. of Patients & Percentage \\
\hline $0-15$ & 29 & 46 \\
\hline $15-45$ & 20 & 32 \\
\hline $45-90$ & 3 & 4 \\
\hline \multicolumn{3}{|c|}{ Table 11. Post-Op Hospital Stay } \\
\hline
\end{tabular}

\begin{tabular}{|c|c|c|}
\hline Events & No. of Pts. & Percentage \\
\hline Discharge & 58 & 93 \\
\hline Obstruction & 1 & 1 \\
\hline Anastomotic leak & 1 & 1 \\
\hline Erosive ulcer at FJ site & 10 & 16 \\
\hline Wound dehiscence & 2 & 2 \\
\hline Perforation & 6 & 10 \\
\hline $\begin{array}{c}\text { Post anastomotic } \\
\text { Oesophageal stricture }\end{array}$ & 1 & 1 \\
\hline \multicolumn{2}{|c|}{ Table 12. Post-Op Events } \\
\hline
\end{tabular}

\section{DISCUSSION}

LYE is the most common ingested caustic in west, acid ingestion is a commoner cause of UGIT injury in our country. Childhood injuries are usually accidental while suicide is frequent motive in young adults. Most of the patients in present study consumed toilet cleaners which are cheap and easily available. In the present study HCL was the commonest agent ingested in $90 \%$ (55.8). In studies by Zargar et al[1] from Chandigarh HCL (19/41) Commonest acid ingested, whereas in series of Dilawari et al[2] $\mathrm{H}_{2} \mathrm{SO}_{4}$ was the commonest (10/16) ingested. In study by Dilawari et al, the mean age was 27 years (Range 16-60 years). There were 12 men and 4 women. All of them belong to low socio-economic status. In 11 patients the injury was accidental while in 5 patients was a suicidal attempt. In study by Tohda et al[3] there were 61 men and 34 women with an average age of 37.2 years (Range 17-81). Ingestion was due to a suicide attempt in 49 patients and accidental in 46 patients. In present study 74\% (46/62) patients ingested corrosive with suicidal intention. In study by Shiva Kumar et al[4] $88.6 \%$ ingested with suicidal intension. In our study most of the patients presented to the surgery department with mean interval between ingestion and admission being 10 days; in contrast to mean interval of 14 hours by Dilwari et al. In a study by Sarah et al there were 69 men and 39 women with an average age of 37 years (range 17 to 81). Ingestion was due to a suicide attempt in 56 patients and accidental in 52 patients. The ingested agents were strong acid in 17 patients, strong alkalis in 32. In study by Cheng et $\mathrm{al}^{[5]}$ in total of 273 patients consisting of 127 (47\%) males and 146 females $(53 \%)$ with a mean age of $43.77 \pm 18.46$ were present. Ingestion intent was primarily attributed to suicide (n $=194,71.06 \%)$ while $28.94 \%(n=79)$ of the cases were accidental. In a study Ertekin et al[6] the group consisted of 29 females and 24 males with a mean age of 33 years (Range 15 to 77). Caustic ingestion was accidental in 31 (59\%) and suicidal in $22(41 \%)$. Twenty-five (47\%) patients had history of acid ingestions, 21 (40\%) alkaline and 7 (12\%) unknown agents. In study by Subratadey et al[7] of 65 patients among whom 12 were males and 53 females giving a M:F ratio of $1: 4.5$. The mean age of the patients was $29.8+11.04$ yrs. Most of the cases belonged to 20-30 years of age. The present study revealed female preponderance of oesophageal strictures and were mostly suicidal attempts. Most of the patients had education above the secondary level and $13.8 \%$ of the study population were students. Most of the patients belonged to low 
socioeconomic class. The offending agent was found to be acids (Muriatic acids, Harpic and others) in all the cases. Attempted suicide was the reason for ingestion in $57(87.7 \%)$ of the patients while it was accidental in $7(10.7 \%)$ others. In one of the females it was suspected to be a case of homicide as mentioned by the relatives.

In our study there were $62 \%$ men and $38 \%$ women with reference range of age of 15 to $70 \mathrm{yrs}$., with mean age of $26 \mathrm{yrs}$. The number of patients who ingested acid were 92\% (57/62) only a few of them ingested alkali $8 \%(5 / 62)$. Ingestion was due to a suicide attempt in $74 \%(46 / 62)$ patients and accidental in $24 \%(15 / 62)$ patients and homicidal in $2 \%$ (1/62) patients. Amount of corrosive ingested remained in range from $50 \mathrm{ml}$ to $1000 \mathrm{ml}$ which was asked during the history taken from patients and attenders. Patients those belonged to low socio-economic class were 77\% (47/62) and $23 \%(15 / 62)$ were middle class. No patients of high class were recorded.

Sialorrhoea (90\%) epigastric pain (60\%) \& dysphagia $(62 \%)$ were the commonest symptoms encountered in study by Sudharsi et al.[8] In a study by Cowan et al [9] 65 patients were symptomatic, 61 reported sore throat (50), abdominal pain (21), chest pain (17), dysphagia (13).In study by Rodriquez et al,[10] the most frequent signs and symptoms were vomiting, abdominal pain, nausea and sore throat. Injuries were present in $100 \%$ of patients who ingested acid and 33\% who ingested alkali had lesions. Five (5\%) patients had oropharyngeal lesions, $24(26 \%)$ in the oesophagus, 36 $(40 \%)$ in the stomach and $12(13 \%)$ in the duodenum. In study by Pramodmirji et al[11] the predominant symptom was pain and most had oesophageal injuries. The grade 2 injury was the most common type of injury. In study by Subrata et al., acute symptoms like peri-oral ulceration was present in 17 cases (26.15\%), while aspiration pneumonitis was present in 7 cases (10.8\%). Most (41.6\%) of the patients attended this hospital after a period of 1 month of the injury. Dysphagia to solids was found to be the commonest presentation and was reported by $53.8 \%$ patients, followed by absolute dysphagia in the rest. Vomiting was present in cases of Gastric Outlet Obstruction $(10 \%)$ Whereas in study by Shiva Kumar et al dysphagia was the commonest symptom (97.1\%). Choudhary et al[12] total of $18(53 \%)$ patients had an associated oesophageal stricture and presented with dysphagia, $15(44 \%)$ patients had features of gastric outlet obstruction, 6 (18\%) had diffuse gastric injury, and $28(82 \%)$ had a segmental lesion. In study by Agarwal et al.,[13] the main presenting complaints were vomiting (75\%), dysphagia (46\%) and significant weight loss (100\%).

In our study, most common symptom is dysphagia present in $95 \%(59 / 62)$, chest pain $65 \%(40 / 62)$, vomiting $47 \%$ $(29 / 62)$, abdominal pain $15 \%(9 / 62)$, drooling of secretions $60 \%$ (37/62), Hematemesis $10 \%(6 / 62)$. The site of lesion is predominantly oesophagus with $23 \%$ mid oesophagus (14/62), 19\% distal oesophagus (11/62), 23\% involving both mid and distal oesophagus (14/62), stomach 16\%(10/62) and single case involving duodenum. Seven out of 62 patients presented to us with signs of acute abdomen with X-ray abdomen revealing gas under diaphragm. Three patients after adequate resuscitation were taken for exploratory laparotomy. Remaining four patients succumbed to resuscitation. $27 \%$ $(16 / 62)$ had severe oesophageal injury. Where in study by Shiva Kumar et al of Chennai 69.2\%\& 65.4\% had diffuse oesophageal \& gastric involvement respectively. Duodenum was relatively spared in majority of patients\& in those involved they were mostly of minor grade \& this can be attributed to pylorospasm\& alkaline $\mathrm{PH}$ of duodenum. There is no great difference in severity of injuries in those who consumed on either on full stomach or on empty stomach. However, the two patients who presented with perforation consumed acid on empty stomach. Presence of epigastric tenderness per abdomen guarding was associated with severe burns of oesophagus (64\%) \& stomach (53\%) however 14\% of patients with normal abdomen had severe upper gastrointestinal injury, so symptoms \& physical examination were unreliable in all cases in determining the severity or extent of injury.

In our study we laid importance on maintenance of nutrition and building up of patients to minimize the effect of primary insult leading to secondary insult in form of complications as strictures. Nutrition in the treatment of acute corrosive intoxications is one of the most important therapeutic processes that largely contribute to faster recovery of the post-corrosive injuries of upper GIT, stabilization of biologic, immunologic and metabolic parameters, and reduction of length of stay in hospital.

Therefore, TPN was initiated immediately after the endoscopic verification of intoxication and lasted until first endoscopic follow-up, when the enteral nutritional support through naso-enteral tubing was started lasting, before the oral feeding or other form of enteral nutrition GJ and FJ was done. That's why feeding jejunostomy was done in all the cases at 2 to 3 weeks or later to maintain nutrition followed by Barium meal and upper gastrointestinal endoscopy and at 6 weeks and decisions were taken accordingly. In our setup doing feeding jejunostomy was also economic and feasible due to high costs of TPN, longer hospital stay. Through FJ, patients were given high protein liquefied diet in form of high protein powder, meshed eggs, honey, curd, pulses. The Calories delivered was intentionally kept more than required up to $3000 \mathrm{kcal}$ leading to better nutritional status of patients. Rationale for such approach is based on the reduction of complications, improvement of patient well-being, easier adjustment of the patient in home conditions (Home enteral nutrition) and reduction of hospital costs. General recommendation includes instalment of GJ or FJ that will enable continuous and quality nutrition for a longer period, maintenance of metabolic-electrolyte balance and stable nutritional status

In our study no complications were encountered during early endoscopy. Endoscopy was not only used for evaluating burns, but was also used in deciding treatment $\&$ in assessing healing of burns. Oesophageal reconstruction was offered to psychologically stable patients after emergency oesophageal resection and for oesophageal strictures that failed endoscopic dilation.

All patients with minor injuries recovered without any sequelae, where as those with severe burns developed acute $\&$ late complications.

In our study oesophageal stricture was present in $75 \%$ cases (46/62), gastric outlet obstruction in $16 \%$ cases $(10 / 62)$, epigastric pain due to GERD in $20 \%$ cases $(12 / 62)$. There was also one case of squamous cell carcinoma which presented almost 40 yrs., after ingestion of acid with metastasis and absolute dysphagia for which Feeding jejunostomy was done. 
In our study six patients presented with signs of acute abdomen with per abdomen tenderness guarding with gas under diaphragm on x-ray abdomen. Three patients died despite of aggressive resuscitation due to peritonitis. In the remaining three, two had gastric perforation one in body and one in prepyloric region for which grahams patch repair was done, one had duodenal perforation which was repaired with feeding jejunostomy done and all discharged remaining three had perforation with deranged counts and managed conservatively with drain placement.

Oesophageal dilation was successful in 29 patients while 10 out of 62 patients had undergone thoracoscopic mobilization of oesophagus with gastric pull up with exploratory laparotomy with resection of diseased segment with open cervical esophagogastric anastomosis and 3 out 62 patients undergone colonic transposition. Gastrojejunostomy for gastric outlet obstruction done in $16 \%$ cases(10/62). Esophagectomy was done in 13 cases. Acute complications of corrosive ingestion occurred in all cases including stricture, gastric outlet obstruction, chest complication in two cases.

In study by Zargar et al, oesophageal injury was seen in $87.8 \%$ of the patients, gastric injury in $85.4 \%$, and duodenal injury in $34.1 \%$. All patients with grade 0,1 , and 2 a injury recovered without sequelae. Acute complications occurred in $39.1 \%$ of the cases, and death in $12.2 \%$. It is significant that all such patients had grade 3 burns. Five of the 8 patients with grade $2 \mathrm{~b}$ injury and all survivors of grade 3 injury developed oesophageal or gastric cicatrization, or both, which subsequently needed endoscopic or surgical treatment

In study by Cheng et al Stricture formation was the most common complication observed in all patients $(n=66$, $24.18 \%)$

Stricture formation typically occurred 2 weeks after caustic ingestion. Management of the 66 patients with a stricture included gastrojejunostomy $(\mathrm{n}=24)$, dilation with endoscope $(\mathrm{n}=21)$, medical treatment $(\mathrm{n}=10)$, esophagectomy ( $n=5)$, jejunostomy $(n=4)$, esophago-colonic bypass $(n=1)$, and nasogastric feeding due to old CVA $(n=1)$. of the 21 patients dilated endoscopically, 11 patients required subsequent surgery due to perforation ( $n=3$, one in the oesophagus, two in the pyloric area) and failure of dilation (n $=8$ ). Gastrojejunostomy were performed due to gastric outlet obstruction or EC junction stricture. Fifty-one patients received surgery due to perforation $(n=6)$ and stricture $(n=$ 34 ), and 11 patients required surgery after endoscopic dilation. Four deaths (in 51 patients who required surgery) were due to multiple organ failure, sepsis, or hematemesis.

In study by Agarwal et al. Most patients had antropyloric strictures $(\mathrm{n}=22)$; in 6 patients, however, near-total or total gastric involvement was observed. Thirteen (46\%) patients had associated strictures of the oesophagus; of these, 7 responded to oesophageal dilation. Strictures of the stomach were managed with procedures involving resection like distal gastrectomy $(\mathrm{n}=16)$, subtotal gastrectomy (1) or total gastrectomy (3) and oesophagogastrectomy (1) in 21 (75\%) patients. The remaining 7 patients underwent bypass procedures like gastrojejunostomy (5), stricturoplasty (1), and colonic bypass of oesophagus and stomach (1). Three patients had entero-cutaneous fistulae in the postoperative period. One patient died in hospital of septicaemia and malnutrition.

In our study we also found association between psychiatric disorder and corrosive ingestion $40 \%$ patients have history of depression and 33\% have history of addiction to alcohol and tobacco. In our study post op complications were obstruction in one patient of gastric pull up who was re-explored and then postop was uneventful, anastomotic leak in one patient, erosive ulcer at FJ site in 10 patients, wound dehiscence in two patients, post anastomotic oesophageal stricture in one patient who was re-explored and subjected to manual dilation. All complications were managed well with an overall mortality of $6 \%$ and present only with initial severe injuries.

\section{CONCLUSIONS}

Corrosive acid is one of the commonest suicidal agents ingested. Signs and symptoms are unreliable guide to estimate severity in all cases. Early flexible fibre optic endoscopy has a crucial role in both diagnosing the severity of injury as well as in management.

Main principle in managing the patients with corrosive injury to upper gastric intestinal tract is that patient should be evaluated individually.

- Corrosive injury is more common in males.

- Most of the patients were of younger age.

- Acid ingestion was more common than alkali ingestion.

- Most corrosive ingestions had suicidal intentions.

- Most of the patients with corrosive injuries can be managed conservatively with follow up for the stricture, which is the most common complication that is often treated by dilatation.

- Most common symptoms were dysphagia, chest pain, vomiting, abdominal pain, drooling of secretions, Hematemesis.

- Most common affected part of gastrointestinal tract is oesophagus followed by stomach and duodenum.

- Most common acute complication is oesophageal stricture followed by gastric outlet obstruction, GERD, chest complications, carcinoma rarely.

- Most of corrosive ingestions were in low socioeconomic class.

- Corrosive ingestion done for suicidal intentions were common among alcoholics and patients of depression.

\section{REFERENCES}

[1] Zargar SA, Kochar R, Nagi B, et al. Ingestion of strong corrosive alkalis: spectrum of injury to upper gastrointestinal tract and natural history. Am J Gastroenterol 1992;87(3):337-41.

[2] Dilawari JB, Singh S, Rao PN, et al. Corrosive acid ingestion in man - clinical and endoscopic study. Gut 1984;25(2):183-7.

[3] Tohda G, Sugawa C, Gayer C, et al. Clinical evaluation and management of caustic injury in the upper gastrointestinal tract in 95 adult patients in an urban medical center. Surg Endosc 2008;22(4):1119-25.

[4] Shivakumar S, Rajan SK, Venkataraman J, et al. Corrosive ingestions - a study of acute complications in 35 patients. JAPI 2003;51:1283.

[5] Cheng HT, Cheng CL, Lin CH, et al. Caustic ingestion in adults: the role of endoscopic classification in predicting outcome. BMC Gastroenterol 2008;8:31.

[6] Ertekin C, Alimoglu O, Akyildiz H, et al. The results of caustic ingestions. Hepatogastroenterology 2004;51(59):1397-400. 
[7] Dey S, Dey I, Das B, et al. Epidemiology of ooesophageal stricture and its outcome: a study among patients attending a tertiary hospital of Kolkata. Al Ameen J Med Sci 2013;6(2):176-9.

[8] Sudarsi B, SudhaRani KVL, Siddeswari R, et al. Clinical and endoscopic study of upper GI manifestation in corrosive acid ingestion. International Journal of Scientific and Research Publications 2015;5(2):1-5.

[9] Cowan T, Foster R, Isbister GK. Acute oesophageal injury and strictures following corrosive ingestions in a 27 year cohort. Am J Emerg Med 2017;35(3):488-92.

[10] Rodríguez VBO, Monge SE, Montes TP, et al. Caustics injuries in the upper gastrointestinal tract: clinical and endoscopic features. Rev Gastroenterol Peru 2016;36(2):135-42.
[11] Mirzi P, Joshi C. Management of corrosive injuries of the upper gastrointestinal tract. J Clin Diagn Res 2011;5(5):944-7.

[12] Chaudhary A, Puri AS, Dhar P, et al. Elective surgery for corrosive-induced gastric injury. World J Surg 1996;20(6):703-6.

[13] Agarwal S, Sikora SS, Kumar A, et al. Surgical management of corrosive strictures of stomach. Indian J Gastroenterol 2004;23(5):178-80. 